\title{
Social Network Analysis as an Analytic Tool for Interaction Patterns in Primary Care Practices
}

\author{
Jobn Scott, $M D, P b D^{1,2}$ \\ Alfred Tallia, $M D, M P H^{1,2}$ \\ Jesse C. Crosson, $\mathrm{PbD}^{1,2,4}$ \\ A. Jobn Orzano, MD, MPH ${ }^{1,2}$ \\ Christine Stroebel, $M P H^{1,2}$ \\ Barbara DiCicco-Bloom, RN, $P b D^{1,2}$ \\ Dena O'Malley, BA ${ }^{1,2}$ \\ Eric Shaw, $P b D^{1,2}$ \\ Benjamin Crabtree, $\mathrm{PbD} \mathrm{D}^{1,2,3}$ \\ 'Department of Family Medicine, \\ Robert Wood Johnson Medical School, \\ University of Medicine and Dentistry of \\ New Jersey, New Brunswick, NJ \\ ${ }^{2}$ Center for Research in Family Practice \\ and Primary Care, Cleveland, Ohio \\ ${ }^{3}$ Cancer Institute of New Jersey, New \\ Brunswick, NJ \\ ${ }^{4}$ University of Medicine and Dentistry \\ of New Jersey, New Jersey Medical School, \\ Newark, NJ
}

Conflicts of interest: none reported

\section{CORRESPONDING AUTHOR}

John G. Scott, MD, PhD

Department of Family Medicine

One Worlds Fair Drive

Somerset, NJ 08873

scottjg@umdnj.edu

\begin{abstract}
PURPOSE Social network analysis (SNA) provides a way of quantitatively analyzing relationships among people or other information-processing agents. Using 2 practices as illustrations, we describe how SNA can be used to characterize and compare communication patterns in primary care practices.
\end{abstract}

METHODS Based on data from ethnographic field notes, we constructed matrices identifying how practice members interact when practice-level decisions are made. SNA software (UCINet and KrackPlot) calculates quantitative measures of network structure including density, centralization, hierarchy and clustering coefficient. The software also generates a visual representation of networks through network diagrams.

RESULTS The 2 examples show clear distinctions between practices for all the SNA measures. Potential uses of these measures for analysis of primary care practices are described.

CONCLUSIONS SNA can be useful for quantitative analysis of interaction patterns that can distinguish differences among primary care practices.

Ann Fam Med 2005;3:443-448. DOI: 10.1370/afm.344.

\section{INTRODUCTION}

$\mathrm{P}$ rimary care practices are complex systems that are characterized by dynamic patterns of interactivity among practice members and their environment. ${ }^{1-3}$ One feature of complex systems is the property of emergence, which is the tendency of organized patterns to emerge that cannot be predicted from the properties of individual parts of the system. ${ }^{4}$ Thus, to understand how primary care practices function, it is necessary to study not only the individuals within the practice or individual practice components but also the relationships among individuals. ${ }^{5}$ Study of such patterns and how they change with time or in response to interventions requires an ability to look at the entire complex web of relationships and interactions within a primary care practice. Although qualitative description $^{6-10}$ and practice genograms $\mathrm{s}^{11}$ have demonstrated utility for understanding the complex interactions in practices, a tool that captures quantitative aspects of the patterns of relationships within practices would be a useful aid in studies of primary care practices. Social network analysis (SNA) is such a tool.

SNA combines the concept of the sociogram (a visual representation of relationships in a social group) with elements of graph theory to analyze patterns of interaction among people in various kinds of networks, allowing quantitative comparisons between different network structures. ${ }^{12}$ There is a large body of scholarly literature describing the use of SNA. Much of this work addresses the basic science of SNA, that is the development of 
theoretical models of network organization and the mathematical derivation of quantitative measures of network characteristics. ${ }^{13}$ More recent work examines the association of these quantitative measures with organizational performance outcomes. Cummings and Cross, for example, found that degree of hierarchy, core-periphery structure, and structural holes of leaders correlated negatively with performance in 182 work groups in a large telecommunications company, ${ }^{14}$ and Aydin et al found that increased network communication density was associated with higher use of an electronic medical record system by nurse practitioners and physician's assistants. ${ }^{15}$ There have also been studies showing how network parameters change with time. Shah, for example showed that network centrality decreased after downsizing in a consumer electronics firm, ${ }^{16}$ whereas Burkhardt and Brass documented increased network centrality after introduction of a new computer system in a federal agency. ${ }^{17}$

In this article, using data from 2 primary care practices as examples, we detail SNA measures that can be used to quantify patterns of decision making and discuss how these measures could be used to facilitate the design and measure the outcomes of interventions to change organizational behavior in primary care practices.

\section{METHODS}

The data for the example practices were collected as part of a large, group-randomized clinical trial of primary care practices designed to evaluate a practice improvement intervention funded by the National Heart, Lung, and Blood Institute. Trained observers collected data for 2 weeks in each practice. They directly observed interactions among the office staff and clinicians, conducted key informant interviews of clinicians and staff, tape-recorded in-depth interviews with a sample of practice participants, and collected samples of various practice documents. Observers recorded brief jottings throughout the day and expanded these each evening into extensive field notes. A practice environment template, which detailed data domains for observation, guided data collection. These baseline data were available on 30 primary care practices in the intervention group. We chose the 2 example practices for this article because they illustrated maximal variation in methods of decision making based on our initial analysis of the qualitative data.

\section{Construction of the SNA Matrix}

SNA analyzes patterns of connections (ties) among information-processing agents (nodes). Data are recorded in the form of an adjacency matrix, where each node is assigned both a column and a row in the matrix. A matrix constructed in this way will have two cells representing the intersection of any 2 nodes, 1 above and 1 below the diagonal. If a connection or tie exists between 2 nodes, then a 1 (or another positive number representing the strength of the tie) is entered in the matrix cell representing the intersection of these 2 nodes. If no tie exists, then a 0 is entered. It is not necessary that the 2 cells for each pair of notes have the same value. For example, in Figure 1A, A consults $\mathrm{B}$ when making a decision, but $\mathrm{B}$ does not consult $\mathrm{A}$. In this case, the cell at the intersection of row $\mathrm{A}$ and column B would contain a 1, but the intersection of row $\mathrm{B}$ and column A would contain a 0 . A matrix that has this property is called a directed matrix. If the tie being studied is not directional (ie, if $A$ talks to $B$, then $\mathrm{B}$ must also talk to $\mathrm{A}$ ), then the matrix cells below the diagonal are identical to those above the diagonal and are ignored in the SNA calculations (Figure 1B).

SNA data are usually collected using interviews or surveys. Each member of the network under study is asked to identify every other member with whom he or she has the interaction. For example, a survey item for an SNA study designed to identify decision-making patterns in a network might be constructed as follows: "When you need to solve a problem related to your work, whose input (by e-mail or telephone, or in person) do you regularly seek?" Survey or interview responses are then tabulated and entered in an adjacency matrix as described above.

Because our data consisted of ethnographic field notes rather than survey responses, our approach to constructing the SNA matrices was somewhat more
Figure 1. Examples of adjacency matrices.
A. Directed Adjacency Matrix

\begin{tabular}{|c|c|c|c|}
\hline & A & B & C \\
\hline A & --- & 1 & 0 \\
\hline B & 0 & -- & 1 \\
\hline C & 1 & 1 & -- \\
\hline
\end{tabular}

B. Undirected Adjacency Matrix

\begin{tabular}{|c|c|c|c|}
\hline & A & B & C \\
\hline A & -- & 1 & 0 \\
\hline B & 1 & --- & 1 \\
\hline C & 0 & 1 & -- \\
\hline
\end{tabular}


complex than the method described above. A team consisting of the observers who had recorded the data for the practices and a family physician analyzed the field notes and the transcribed interviews. Each team member individually constructed a social network adjacency matrix for both practices using a spreadsheet (Microsoft Excel) with each practice member assigned both a column and a row. For every person represented on a row of the spreadsheet, team members used qualitative data to answer the question, "Whom does this person consult when significant decisions need to be made in the practice?" For each column in the row, the entry of a 1 or 0 indicated the presence or absence of consultation of that practice member by the person represented on the row. This resulted in a directed as opposed to an undirected matrix, meaning in this case that connections between members were not necessarily reciprocal. Reciprocal connections would occur only if 2 members consulted each other when making decisions.

Unlike structured interviews or surveys, these ethnographic field notes may not provide specific information about each pair of practice members; however, they provide important contextual data for interpreting the SNA results. Statements or observations often describe the interaction of an individual with a group of practice members or interactions between groups. Thus we were able to assign values in the matrix to all the members in each group. In practice 1, for example, we assigned 0 to all the columns for the practice leader, whom we will call "Dr. Smith," indicating that he consulted no one in the practice when making decisions. The following illustrates how data elements from observation, in-depth interviews, and key informant interviews were used to assign those values:

Observations-Practice leader: "Dr. Smith seems to have a very hands-on approach to management of his office. Regarding office organization in decision making, I noticed that most of the decision-making seems to come from Dr. Smith and that there is little in the way of staff empowerment. Decisions are communicated throughout the practice via memo and not very systematically."

In-depth interviews-Office manager: "Long-term goals are set by Dr. Smith, who has a clear goal and change is managed principally by Dr. Smith. Decisionmaking tends to be top-down and all financial management decisions are made by Dr. Smith." Front desk supervisor: "When significant changes need to be made, Dr. Smith makes them. Dr. Smith often sets policies and doesn't follow them himself." Dr. Smith (referring to a new electronic medical record system): "I came up with those plans and I tried to get (the office manager) and the staff to enact the goals I recommended."

Key informant interviews-The office manager: "Reports that Dr. Smith generally doesn't appreciate some of the expertise around. She describes a sort of micromanaging that he does." The nursing supervisor: "Reports that one thing that she does want to mention and make sure it gets into the notes is that Dr. Smith often does not hear when he is spoken to."

Matrix values for the remaining practice members in practice 1 and practice 2 were assigned in similar fashion using the 3 kinds of qualitative data noted above. The team met together to share the individual matrices. There were only minimal differences among the observers, which were resolved by consensus. The resulting matrices were then imported into UCInet ${ }^{18}$ and KrackPlot $^{19}$ software to compute several quantitative measures of network structure for each of the 2 practices.

\section{RESULTS}

\section{SNA Network Diagrams}

Using NetDraw, a program within the UCInet suite, we constructed a visual representation of the networks, illustrating the web of decision-making consultations in each entire network. The network diagrams from our example practices are shown in Figure 2. An arrow leading from 1 member to another indicates that the first member consults the second member when making decisions. A double-headed arrow between 2 members indicates that both members consult each other in decision making. It is clear from inspection of these 2 diagrams that decision-making consultation patterns are different in these 2 practices. Practice 1 has a hierarchical structure. There are no 2-way arrows. The practice leader, MD1, holds all final decision-making authority, yet he seldom consults the office staff when he makes decisions. Practice 2 has a much more collaborative decision-making process, with members empowered to make some decisions on their own. The network diagram is much denser, and there are many 2 -way arrows. The visually apparent differences in the 2 practices can be quantified, as described below.

\section{SNA Quantitative Measures}

Some of the quantitative measures developed for use in SNA include density (a measure of the relative number of connections), clustering coefficient (the tendency of the network to aggregate in subgroups), centralization, (the degree to which a network approaches a perfectly symmetric or "star" network), and hierarchy (the extent to which network relations are ordered). We used these measures in our examples and constructed these measures as follows.

\section{Network Density}

The first measure constructed was network density. The density of a network is the number of actual connections between members divided by the number of pos- 
Figure 2. Network diagrams.

Practice 1

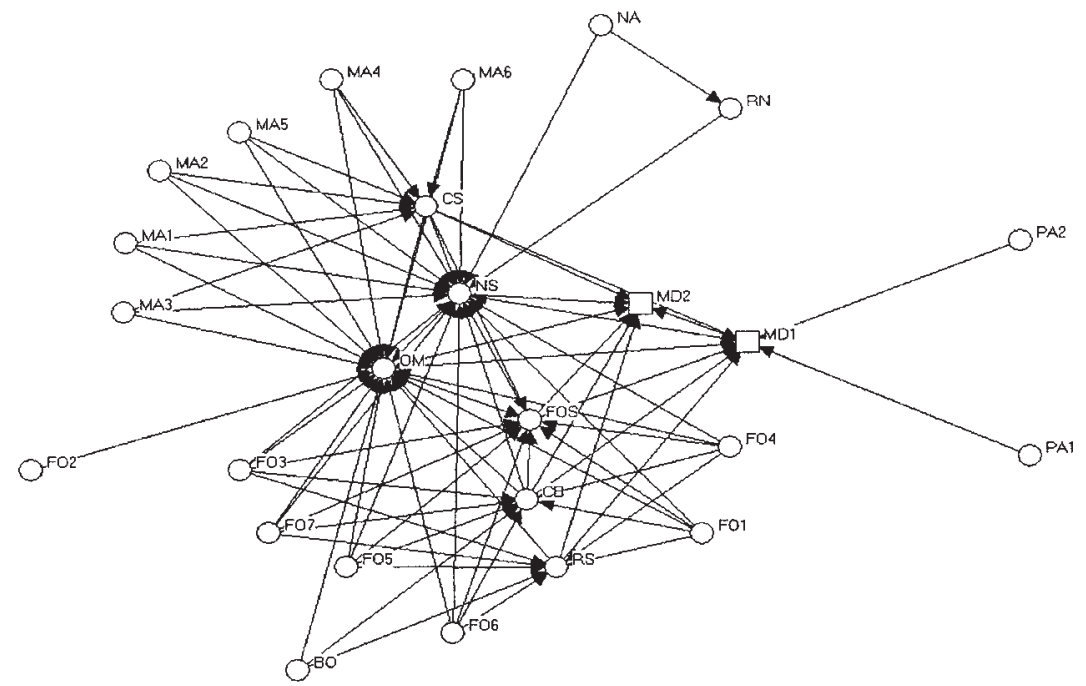

Circles - Females

Squares - Males

Triangles - Outside Organizations

$\begin{array}{llllll}\text { MD1 } & \text { Practice Owner - MD } & \text { MD2 } & \text { Partner - MD } & \text { F05 } & \text { Front Office } \\ \text { NS } & \text { Clinical Supervisor } & \text { PA1 } & \text { Physician's Assistant } & \text { FO6 } & \text { Front Office } \\ \text { CB } & \text { Chief Biller } & \text { PA2 } & \text { Physician's Assistant } & \text { FO7 } & \text { Front Office } \\ \text { RS } & \text { Referral Specialist } & \text { FO1 } & \text { Front Office } & \text { BO } & \text { Billing Office } \\ \text { OM } & \text { Office Manager } & \text { FO2 } & \text { Front Office } & \text { RN } & \text { Nurse - RN } \\ \text { FOS } & \text { Front Office Supervisor } & \text { FO3 } & \text { Front Office } & \text { NA } & \text { Nurse Assistant } \\ \text { NS } & \text { Nursing Supervisor } & \text { FO4 } & \text { Front Office } & \text { MA1 } & \text { Medical Assistant }\end{array}$

MA2 Medical Assistant

MA3 Medical Assistant

MA4 Medical Assistant

MA5 Medical Assistant

MA6 Medical Assistant

Practice 2

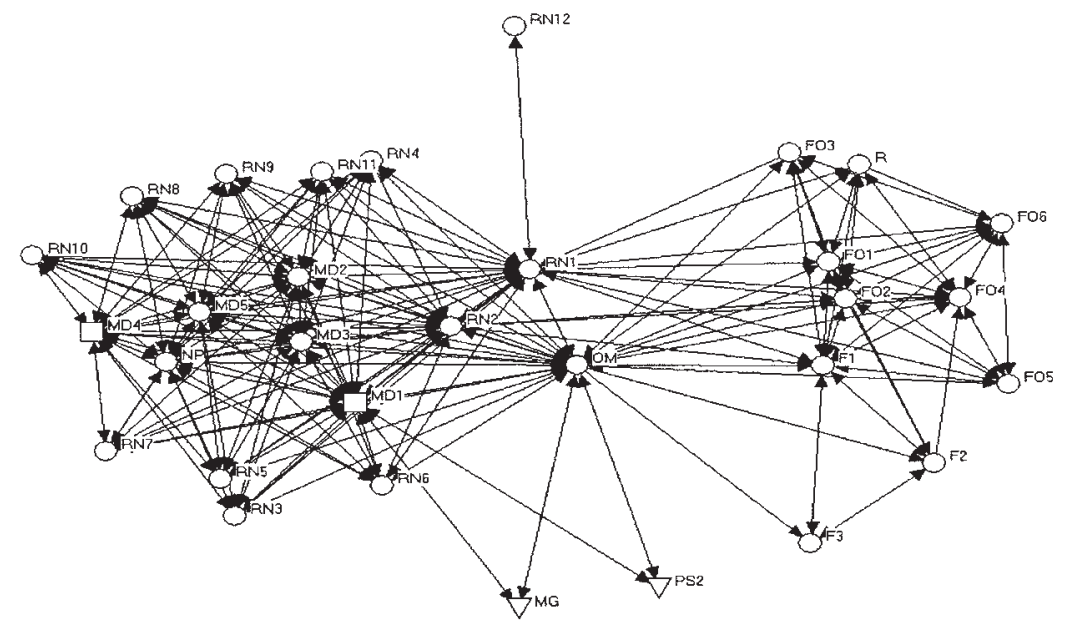

Circles - Females

Squares - Males

Triangles - Outside Organizations

$\begin{array}{ll}\text { MG } & \text { Management Group } \\ \text { PS2 } & \text { Practice Site 2 } \\ \text { OM } & \text { Office Manager } \\ \text { F01 } & \text { Front Office } \\ \text { F02 } & \text { Front Office } \\ \text { F03 } & \text { Front Office } \\ \text { F04 } & \text { Front Office } \\ \text { F05 } & \text { Front Office }\end{array}$

$\begin{array}{ll}\text { FO6 } & \text { Front Office } \\ \text { F1 } & \text { Filing } \\ \text { F2 } & \text { Filing } \\ \text { F3 } & \text { Filing } \\ \text { R } & \text { Referrals } \\ \text { MD1 } & \text { Lead Physician } \\ \text { MD2 } & \text { Physician } \\ \text { MD3 } & \text { Physician }\end{array}$

MD4 Physician

MD5 Physician

NP Nurse Practitioner

RN6 Nurse - RN

RN7 Nurse - RN

RN8 Nurse - RN

RN9 Nurse - RN

RN10 Nurse - RN

RN11 Nurse - RN

RN2 Nurse - RN

RN3 Nurse - RN

RN4 Nurse - RN

RN5 Nurse - RN 
sible connections. Density values range from 0 to $1 .{ }^{12}$ In these decision-making networks, higher density indicates a greater degree of interaction among the members in the process of making decisions. In our example practices, the practice 2 network is more than twice as dense as the practice 1 network, indicating that there are many more decision-making interactions in practice 2 than in practice 1 (Table 1 ).
Table 1. Social Network Analysis Quantitative Measures

\begin{tabular}{lcc}
\hline Measure & Practice 1 & Practice 2 \\
\hline Network density (SD) & 0.1570 & 0.3398 \\
& $(0.3638)$ & $(0.4136)$ \\
Clustering coefficient & 0.223 & 0.590 \\
Hierarchy & 0.93 & 0.00 \\
Centralization - indegree, \% & 73.440 & 57.889 \\
Centralization - outdegree, \% & 6.880 & 64.778 \\
\hline
\end{tabular}

\section{Clustering Coefficient}

The clustering coefficient is the likelihood that any 2 nodes that are connected to the same node are connected themselves. ${ }^{20}$ For these networks, the clustering coefficient measures the degree to which decision making is done in collaborative groups. In our example practices, the clustering coefficient in practice 2 is more than 2.5 times greater than in practice 1 , indicating that more collaborative groups exist in practice 2 than practice 1 (Table 1 ).

\section{Hierarchy}

Hierarchy is the degree to which the network approaches a perfect hierarchy, that is, the degree to which all relations are unidirectional. An organization chart would be an example of a perfect hierarchy. Hierarchy values were calculated using KrackPlot software. ${ }^{19}$ Practice 1 has a very high hierarchy value, whereas the hierarchy value of practice 2 is 0 (no unidirectional relations) (Table 1 ).

\section{Centralization}

Centralization is the degree to which a network approaches the configuration of a "star" network. A star network has 1 node in the center that connects to all other nodes. No nodes have connections to any other node except the central node. The centralization score is expressed as a percentage and can vary from 0 (every member is connected to every other member) to 100 (all members are connected to only 1 member). The centralization percentage thus indicates the degree of asymmetry in the distribution of connections in the network. A high centralization score indicates that some members have many more connections than others. For these directed decision-making networks, there are 2 components to centralization. High indegree centralization would indicate that a small number of members are consulted by the rest of the members. High outdegree centralization would indicate that a small number of members do most of the consulting of others. ${ }^{21}$ Table 1 shows the indegree and outdegree centralization percentages for practices 1 and 2. Both show a relatively high degree of centralization, but practice 1 has much more marked asymmetry in the indegree and outdegree percentages than practice 2 .

\section{DISCUSSION}

It is easy to see from the network diagrams that decision-making patterns differ widely in our 2 example practices. The SNA measures, however, allow us to compare several aspects of those pattern differences quantitatively. Nevertheless, there are, some limitations of both the method and our sample data that should be kept in mind. SNA differentiates members of a network only by the pattern of interactions of each member. It is not a good tool, therefore, for measuring how individual differences in members affect the function of an organization. The quantitative measures provided here are for illustrative purposes to demonstrate the kinds of SNA measures that can be used for structural analysis of organizations. We recognize that because we calculated these measures from qualitative data, which required imputing data for some ties between individual nodes, they may be different than had they been calculated from survey data.

The measures we calculated have been associated with performance outcomes in other organizations $\mathbf{s}^{14,22,23}$ and have been used to measure organizational change with time. ${ }^{17,24}$ Although we cannot make any statistical inferences from the differences in only 2 practices, adaptations of regression and correlation statistics have been developed for use with network data ${ }^{25,26}$ that provide a practical way to examine association of network parameters with performance outcomes in large numbers of practices. We might hypothesize based on the outcome studies cited above, for example, that network density would correlate positively with practice adherence to treatment guidelines for hypertension, and that degree of hierarchy would correlate negatively. These hypotheses could be tested using network data. Significance testing using SNA measures could also be used in randomized controlled trials to evaluate the impact on decision making or other communication patterns of interventions aimed at organizational change.

Another possible use of SNA quantitative measures would be to help tailor interventions in practices based on their network parameters. An intriguing article by McGrath and Krackhardt ${ }^{27}$ explores how different network configurations might predict what sorts of 
interventions would be most effective in producing sustainable organizational change.

We used decision-making patterns in this analysis, but the technique would lend itself to the study of any other observed interaction among agents in the complex social systems of primary care practices, such as office communication patterns, clinical information flow, or referral patterns. SNA could also be used to complement and triangulate other quantitative measures of organizational performance that use survey methodology. ${ }^{28}$

SNA is a useful tool for quantitative analysis of the complex systems represented by primary care practices A broad range of potential applications of this tool is possible, including using it to help design interventions to promote practice organizational change.

To read or post commentaries in response to this article, see it online at http://www.annfammed.org/cgi/content/full/3/5/443.

Key words: Evaluation studies; health care delivery; health services research; social networks

Submitted October 3, 2004; submitted, revised, April 21, 2005; accepted April 25, 2005

Funding support; This study was funded by a National Heart Lung Blood Institute Grant R01 HL070800-01. Analysis of these data was also supported in part by a Research Center grant from the American Academy of Family Physicians (Center for Research in Family Practice and Primary (are).

Acknowledgments: The authors wish to thank the clinicians and staff of the practices who were willing to open their practices up for us.

\section{References}

1. Miller WL, Crabtree BF, McDaniel R, Stange KC. Understanding change in primary care practice using complexity theory. J Fam Pract. 1998;46:369-376.

2. Miller WL, McDaniel RR, Jr., Crabtree BF, Stange KC. Practice jazz: understanding variation in family practices using complexity science. J Fam Pract. 2001;50:872-878.

3. Crabtree BF. Primary care practices are full of surprises! Health Care Manage Rev. 2003;28:279-283; discussion 289-290.

4. Holland JH. Emergence: From Chaos to Order. Reading, Mass: Perseus Books; 1999.

5. Satish U. Behavioral complexity: a review. J Appl Soc Psychol. 1997;27:2047-2067

6. Aita V, Mcllvain H, Susman J, Crabtree B. Using metaphor as a qualitative analytic approach to understand complexity in primary care research. Qual Health Res. 2003;13:1419-1431.
7. Kairys JA, Orzano J, Gregory P, et al. Assessing diversity and quality in primary care through the multimethod assessment process (MAP). Qual Manag Health Care. 2002;10:1-14.

8. Tallia AF, Stange KC, McDaniel RR, Jr, et al. Understanding organizational designs of primary care practices. J Healthc Manag. 2003;48:45-59; discussion 60-41.

9. Aita V, Dodendorf DM, Lebsack JA, Tallia AF, Crabtree BF. Patient care staffing patterns and roles in community-based family practices. J Fam Pract. 2001;50:889.

10. Crabtree BF, Miller WL, Stange KC. Understanding practice from the ground up. J Fam Pract. 2001;50:881-887.

11. Mcllvain H, Crabtree B, Medder J, Stange KC, Miller WL. Using practice genograms to understand and describe practice configurations. Fam Med. 1998;30:490-496.

12. Scott J. Social Network Analysis: A Handbook. 2nd ed. Thousands Oaks, Calif: Sage Publications; 2000.

13. Borgatti SP, Foster PC. The network paradigm in organizational research: a review and typology. J Management. 2003;29:991-1013.

14. Cummings JN, Cross R. Structural properties of work groups and their consequences for performance. Soc Networks. 2003;25:197-210.

15. Aydin CE, Anderson JG, Rosen PN, Felitti VJ, Weng HC. Computers in the consulting room: a case study of clinician and patient perspectives. Health Care Manag Sci. 1998;1:61-74.

16. Shah PP. Network destruction: the structural implications of downsizing. Acad Management J. 2000;43:101-112.

17. Burkhardt ME, Brass DJ. Changing patterns or patterns of change: the effects of a change in technology on social network structure and power. Administrative Sci Quarterly. 1990;35:104-127.

18. Ucinet for Windows: Software for Social Network Analysis. Cambridge, Mass: Analytic Technologies; 2002.

19. Krackhardt D, Blythe J, McGrath C. KrackPlot 3.0: an improved network drawing program. Connections. 1994;17:53-55.

20. Watts DJ. Small Worlds: The Dynamics of Networks Between Order and Randomness. Princeton, NJ: Princeton University Press; 1999.

21. Freeman LC. Centrality in social networks I: conceptual clarification. Social Networks. 1979;1:215-239.

22. Reagans R, Zuckerman EW. Networks, diversity, and productivity: the social capital of corporate RED teams. Org Sci. 2001;12:502-517.

23. Sparrowe RT, Liden RC, Wayne SJ, Kraimer ML. Social networks and the performance of individuals and groups. Acad Management J. 2001;44:316-325.

24. Burt RS. Decay functions. Soc Networks. 2000;22:1-28.

25. Baker F, Hubert R. The analysis of social interaction data. Soc Methods Res. 1981;9:339-361.

26. Krackhardt D. Predicting with social networks: nonparametric multiple regression analysis of dyadic data. Soc Networks. 1988; 10:359382.

27. McGrath C, Krackhardt D. Network conditions for organizational change. J Appl Behav Sci. 2003;39:324-336.

28. Cameron KS, Quinn RE. Diagnosing and Changing Organizational Culture: Based on the Competing Values Framework. Reading, Mass: Addison-Wesley; 1999. 